\title{
Electricity Demand Impact from Increased use of Ground Sourced Heat Pumps
}

\author{
J. Campillo ${ }^{1}$, Student Member, IEEE, F. Wallin, Member, IEEE, I. Vassileva, Student Member, IEEE \\ and E. Dahlquist, Member, IEEE
}

\begin{abstract}
The use of ground-sourced heat pumps as main heating systems has increased in Sweden in the last fifteen years to the point that it is the country with the highest amount of GSHP in Europe. Heat pumps are chosen by many households due to their economic savings value; In contrast, electricity prices in Sweden have almost doubled since 2006, threatening their economic benefits. It is therefore, essential to understand GSHPs impact on the user's electricity consumption and provide suitable demand-response programs that could help develop a model capable of forecasting consumption and provide decision support information to make the best use of the technology. This paper analyses questionnaire surveys and consumption patterns were evaluated for 322 households with installed GSHPs and different pricing schemes in order to increase the understanding of mass use of this type of heating system.
\end{abstract}

Index Terms-Demand forecasting, Energy Consumption, Heat Pumps, Power Systems, Smart Grids, Electricity Demand.

\section{NOMENCLATURE}

$\begin{array}{ll}\text { CHP } & \text { Combined Heat and Power } \\ \text { COP } & \text { Coefficient of Performance } \\ \text { DH } & \text { District Heating } \\ \text { DR } & \text { Demand Response } \\ \text { EH } & \text { Electric Heating } \\ \text { GSHP } & \text { Ground-Sourced Heat Pump } \\ \text { RTP } & \text { Real-Time Pricing } \\ \text { TOU } & \text { Time-Of-Use } \\ \text { DSM } & \text { Demand-Side Management }\end{array}$

\section{INTRODUCTION}

Sicising weden's energy use in the residential sector in 2010, was $166 \mathrm{TWh}, 40 \%$ of Sweden's total final energy use. Almost $60 \%$ of the sector's energy use is for heating and hot water.

District heating, oil, biofuel and electricity are the main sources of energy used for heating purposes, being the latter the one with the highest usage increase, from $5 \mathrm{TWh} /$ year in 1970 to $29 \mathrm{TWh} /$ year in 1990 . The increase in electricity consumption occurred mainly due to the installation of direct electric heaters and heat pumps; the latter, however, started declining after the that year [1]. One of the main causes of this

Special thanks to the Colombian's national Science, Technology and Innovation administrative department, as well as the Tecnológica de Bolívar University for its financial support during my graduate studies.

Javier Campillo, Iana Vassileva, Fredrik Wallin and Erik Dahlquist are with the Department of Sustainable Development of Society and Technology at Mälardalen University in Västerås, Sweden. (e-mail: first.last@mdh.se) was the active debate on the phase out of nuclear power plants in the energy system over the following years. This debate increased public's concern regarding the use of electricity as an energy source for heating. In year 1995 heat pumps sales hit a minimum of less than 10.000 units sold per year [2].

In year 1995, the Swedish National Board for Technical Development (NUTEK) issued technology procurement on heat pumps and sales started increasing again. [3] At the end of the procurement, ground-sourced heat pumps were chosen. In consequence, these types of heat pump take a large share in the Swedish market for new heat pumps installations [2]. As a result, Sweden currently has the highest amount of GSHP installed in Europe as shown on table 1 [4].

TABLE I.

EUROPEAN GSHP INSTALLED BASE

\begin{tabular}{l|c|c}
\hline \multicolumn{1}{c|}{ Country } & GSHP Installed & $\%$ \\
\hline Sweden & 303600 & $44 \%$ \\
\hline Germany & 117300 & $17 \%$ \\
\hline France & 103500 & $15 \%$ \\
\hline Switzerland & 55200 & $8 \%$ \\
\hline Austria & 48300 & $7 \%$ \\
\hline Finland & 41400 & $6 \%$ \\
\hline Norway & 13800 & $2 \%$ \\
\hline Estonia & 6900 & $1 \%$ \\
\hline TOTAL & 690000 & 1 \\
\hline
\end{tabular}

Ground sourced heat pumps can achieve a 1:3 electricity to heat conversion ratio [5], consequently, its usage growth facilitated a reduction not only of oil-based heating, but also district heating, increasing the overall electricity to heat conversion efficiency in the country. As a main result, in 2009 , the use of electric heating decreased to 19 TWh.

The average cost of a turnkey solution for a GBHP in Sweden is between 11000 and 15000 EUR, while other options such as air-sourced and water-sourced cost between 1500-2300 and 8000-11000 EUR respectively. To reduce the initial cost, installation of heat pumps can apply for a tax reduction scheme approved in December 8, 2008 when renovating and performing extension works in private households [4].

The selection of sources of energy used for heating purposes varies for different housing types; electricity is the most common form of energy used for hot water and heating 
in one and two-dwelling buildings, $14 \mathrm{TWh}$ in electricity were used in 2009 compared to $13 \mathrm{TWh}$ in biofuels, 5 TWh in district heating and 1.5 TWh in oil. This last one has experienced the highest use decline while the use of heat pumps has steadily increased. In year 2009 heat pumps were used in 754.000 one and two-dwelling buildings in Sweden; roughly $40 \%$ of such homes [1].

On the other hand, district heating is the most common form of energy used for heating in multi-dwelling buildings. Its use in 2009 was $22 \mathrm{TWh} ; 91 \%$ of the total energy use for heating and hot water in these types of households; electric heating accounted for only $1 \mathrm{TWh}$ while oil use was $0.4 \mathrm{TWh}$. Overall, oil use for heating continues to decline on all housing types; the total annual use amounted for $0.8 \mathrm{TWh}$ of oil [1].

Biomass burners (pellets) were used to replace oil burners in existing heating systems up to 2006 where there was strong promotion and a subsidy scheme for replacing oil heating; many of the installations, however, did not succeed in meeting user's expectations, mainly due to malfunctioning systems and the required workload by the customers. The subsidy scheme has ended and the pellets price has increased, therefore, a growing number of pellet burners are currently being replaced by heat pumps [4].

\section{ELeCtRICITy DeMAND IMPACT Of HeAt PUMPS}

Abundant precipitation, mountainous ridges and windy spots have allowed the Nordic countries to produce cheap electricity, resulting in the highest demand for electricity per capita all over Europe [6].

In 2010, electricity production in the Nordic countries was $373.3 \mathrm{TWh}$; an increase of $1 \%$ compared with 2009 . The same year, consumption was $396 \mathrm{TWh}$, an increase of $3.8 \%$ compared to 2009. The largest rise in consumption was Finland, due to the recovery of energy intensive industries after the financial crisis and the fact that 2010 was a very dry year and the temperatures during winter season were lower than usual.

Nordic countries' electrical system is very sensitive to environmental factors because of a large use of hydropower and strong connection between temperature and electricity consumption, therefore, 2010 environmental conditions resulted in a production deficit of $30 \mathrm{TWh}$ and a price increase in the electricity spot price compared to 2009. In Sweden alone, In February $22^{\text {nd }}, 2010$, at 8 am, the electricity spot price was $1400 \mathrm{EUR} / \mathrm{MWh}$, about 25 times higher than the average price [6]. During the rest of the year, the mean spot price in Sweden was $54.48 \mathrm{EUR} / \mathrm{MWH}$, the highest annual mean price even recorded. [7]

The electricity price trend has continued to grow and the price per kWh for households in Sweden has almost doubled since 2006 reaching 0.11 EUR cents (99 öre) as shown in Fig. 1 [8].

The main reason for selecting a heat pump as a source of energy for heating purposes is the estimated economic savings over the lifetime of the system [9]. Investment return rates of about six years are expected where GSHPs are used to replace a direct electric heating or combustion boiler [10]. However the recent years' electricity price increase is threatening their economic benefits.

Fortunately, development of smart-metering technologies in Sweden has brought new opportunities for fully exploiting its power system efficiency and reliability, such as price-based demand response (DR) programs at a large scale for household, commercial and industrial users. However, in order to increase users' flexibility and select the best pricing scheme while maintaining a stable electricity demand, energy usage patterns and available tariffs have to be studied together in order to allow GSHP users to still get important economic benefits from their use.

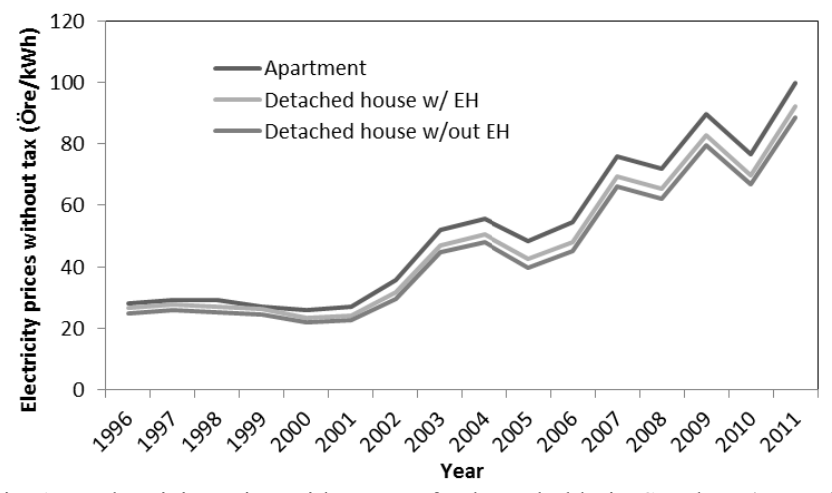

Fig. 1. Electricity price without tax for households in Sweden. (Note that the price per $\mathrm{kWh}$ is given in öre $/ \mathrm{kWh}, 1$ öre $=0.0011 \mathrm{EUR}$ ) [8].

\section{DYNAMIC PRICING SCHEMES}

Dynamic pricing schemes are implemented to encourage users shift power consumption from peak-use times to loweruse times, in order to help balance the load in the power system. This is accomplished by using dynamic pricing mechanisms that are closer to the real cost of electricity supply. The most common methods are Time-of-Use (TOU) where two or more tariffs are used for high-peak and low-peak times; Critical Peak Pricing (CPP) where a flat rate is used unless there is a high-peak critical situation when a very high price per $\mathrm{kWh}$ is applied; Critical Peak Rebate (CPR) where users get paid to lower their consumption under critical peak times and Real-Time Pricing (RTP) where spot market price is applied [11].

To test variable pricing schemes in Sweden, a study was performed to 460 households in 2003 where conventional energy-based (accumulated consumption) and dynamic (hourly-price) pricing scenarios were simulated using users' hourly consumption data in order to understand their economic impact on their electricity bills.

In order to analyse the different pricing schemes, a load factor was used. The load factor was defined as the ratio between the maximum peak loads on the billing period over the average energy consumption. A closer value to 1 represents a smoother load curve. 


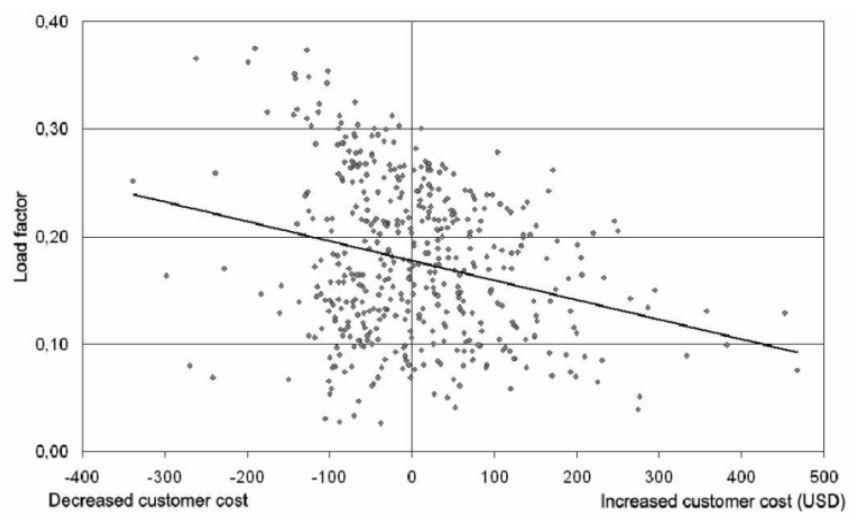

Fig. 2. Difference in customers' yearly electricity cost when applying seasonal demand based tariff compared to the conventional energy tariff.

The results from the study showed than $49 \%$ of the users reduced their electricity bills of up to $330 \mathrm{USD} /$ year while $42 \%$ of the users increased their cost in up to $460 \mathrm{USD} /$ year. Some extreme cases showed savings or increased costs over those values and were treated separately. The results are shown in Fig. 2 [12].

A similar approach was proposed for analysing GSHP electricity consumption impact on the users' electricity bills, in this case, a questionnaire was sent out to 735 households in the Sollentuna municipality, outside Stockholm and their electricity consumption bills were obtained billing periods up to 4 years before the study started.

\section{Methods AND Materials}

A research team at the School of Sustainable Development of Society and Technology (HST) at Mälardalen University performed a survey in a residential area with houses in the Sollentuna municipality in Sweden. The survey consisted of a questionnaire sent out to 735 households composed by 37 questions regarding their housing and energy consumption characteristics. A total of 528 households responded, from which a group of 322 (response rate of $43 \%$ ) was selected formed by households with GSHP installed at least four years before the survey.

The purpose of these household selection criteria was to evaluate the impact on the electricity consumption of installing a new GBHP and its impact on the tariff, taking into account the pricing scheme used in Sollentuna. A comparative energy analysis was performed for four years: two years before and two years after the installation of the GBHP.

The local energy supplier provided hourly electricity consumption information for the four years of the study.

Additionally, the Swedish Meteorological and Hydrological Institute (SMHI) provided hourly outdoor temperature data for the Bromma weather station, the closest to Sollentuna.

In order to analyse only the heating energy consumption that is not affected by outside temperature, weather normalization was applied using SMHI's degree-days for the difference between $17{ }^{\circ} \mathrm{C}$ and the daily mean outdoor temperature.

\section{DISCUSSION \& RESULTS}

\section{A. Questionnaire}

A majority of the households had their own heating systems before the GSHP installation. $75 \%$ of the households said they had floor heating. $10 \%$ of the respondents had heat pumps even before the year of installation ( 23 households had GSHP while 9 had air-air heat pumps). During the period when the questionnaire was sent, already 320 households used GSHP and 12 air-air heat pumps.

\section{B. GSHP Cost Impact}

The average investment made by the homeowners was 120150 SEK (13000 EUR) $(\mathrm{N}=208)$. During the period March - April, DH costs are higher while GSHP are higher from October to February. It is important to bear in mind that these costs are only for the 10 years after the installation of the corresponding heating system. After that period the monthly costs drops with 78 Euros for DH and 92 Euros for GSHP making the GSHP a better alternative if considering a one year period; the life time of the GSHP, however, is limited while the DH needs no new investment making it cheaper in the long term if DH and electricity costs keep the same ratio.

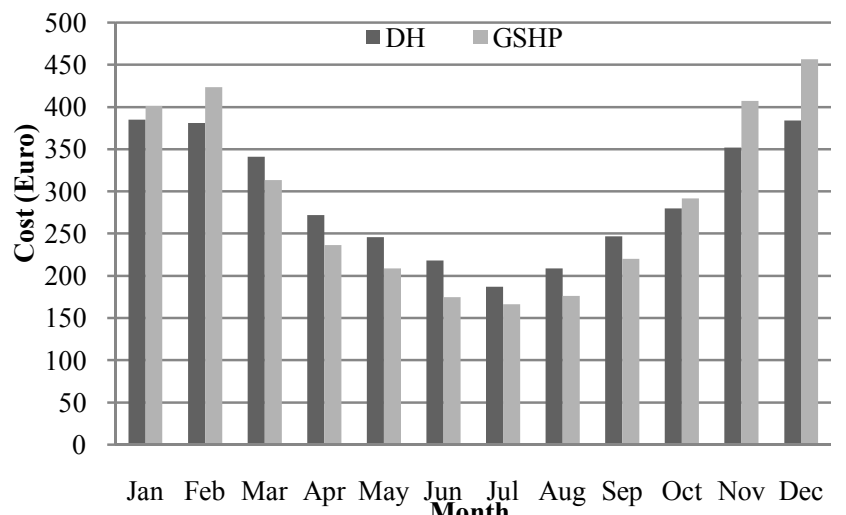

Fig. 3. Average Energy cost comparison between district heating and ground-sourced heat pump for households in Sollentuna

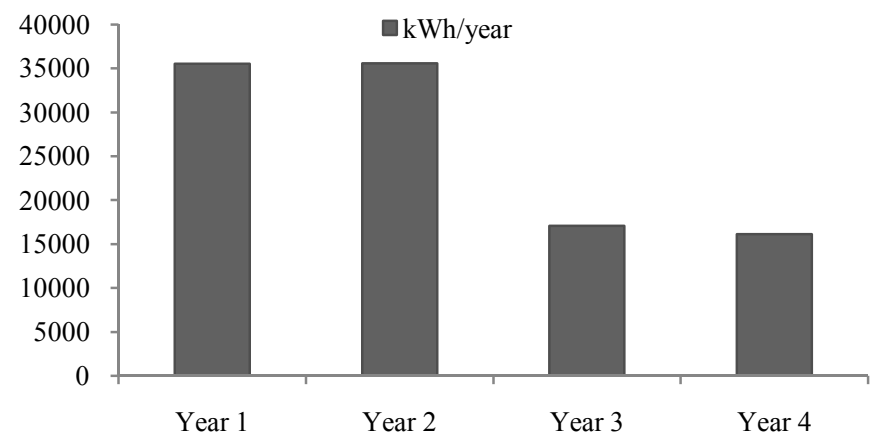

Fig. 4. Annual electricity consumption in households that previously had direct electric water heaters. (Note: The energy consumption data was analysed over a time-span of 5 years, the year where the GSHP was installed was not taken into account in order to make a direct comparison of the consumption before and after installing GSHP over a full year). 
When comparing the electricity consumption reduction in households that previously had conventional electric water heaters, the reduction was $48 \%$ in average with some households saving up to $58 \%$ in their energy usage after installing GSHP, thus, reducing their investment return time.

\section{GSHP Energy Usage Impact}

With the purpose of better understanding the overall impact on electricity consumption for GSHP users, the responses of the questionnaires received from 202 consumers that used different heating sources from GSHP, were analysed. The objective of the analysis was to find households that used other heating sources but with similar physical characteristics as those that used GSHP. At the end, the main required difference was for those households to use only district heating $(\mathrm{DH})$ as main source of heating. Also, in order to reduce noise in the energy consumption data, it was required for the filtered houses to use as minimum auxiliary heating systems as possible. The filtering criteria applied to the consumers are shown in Table II. As a result, energy consumption from 73 users was compared to the one from GSHP users for a period of 5 years.

TABLE II. FILTERING CRITERIA FOR COMPARISON GROUP

\begin{tabular}{l|l}
\hline \multicolumn{1}{c|}{ Household Characteristic } & \multicolumn{1}{c}{ Filtering Criteria } \\
\hline Household Type & Detached House \\
\hline Ventilation System & Natural Ventilation \\
\hline Aux Electrical Boiler? & No \\
\hline Main Heating System & District Heating \\
\hline
\end{tabular}

\section{1) Annual Electricity Consumption}

The average annual electricity consumption was calculated for both the households with DH and those with GSHP. The consumption was calculated in $\mathrm{kWh} / \mathrm{m} 2 /$ year. The results are shown in Fig. 5.

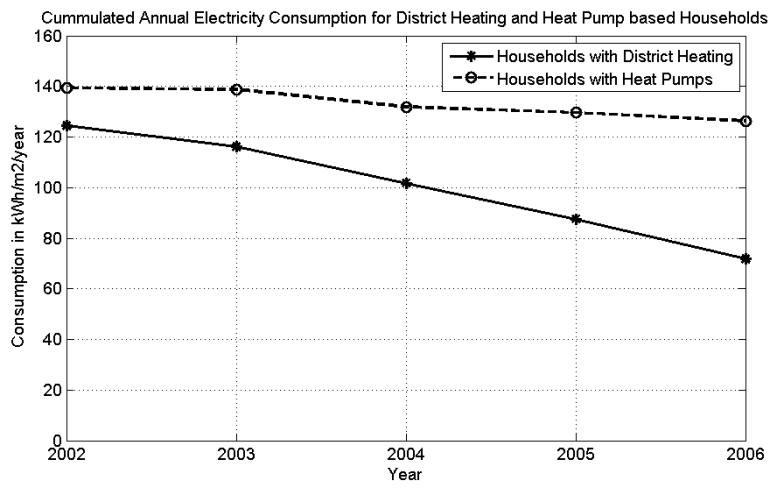

Fig. 5. Annual electricity consumption for DH-based households and GSHP-based households

The results revealed a minimum additional electricity consumption of $11.9 \%$ for GSHP-based households in year 2002 and a maximum additional electricity consumption of
$76.5 \%$ in 2006 , the year with the coldest winter of the 5 years analysed.

Moreover, the annual consumption for GSHP-based households was more stable over the 5 years period with an average of $133.2 \mathrm{kWh} / \mathrm{m} 2 /$ year while DH-based households experienced a continuous decrease in electricity consumption starting with $124.4 \mathrm{kWh} / \mathrm{m} 2 /$ year in 2002 and finishing with $71.76 \mathrm{kWh} / \mathrm{m} 2 /$ year in 2006, almost a $43 \%$ electricity consumption reduction.

Although not enough information for determining the reasons for the sustained consumption reduction in DH-based households was provided from the questionnaires, nor is the purpose of the present paper; several consumers acknowledged to have invested in energy-efficient appliances and to have done renovations in their households in order to reduce energy consumption. This implies that GSHP-based users can be less likely to obtain faster reductions in electricity use from increased use of energy-efficient appliances since HPs energy use is heavily affected by temperature conditions, substantially affecting the overall electricity consumption.

\section{2) Monthly Electricity Consumption}

To continue further analysing temperature impact on GSHP energy use, the monthly electricity consumption was compared between DH-based and GSHP-based households over the 5 years period. The resulting plot is shown in Fig. 6 .

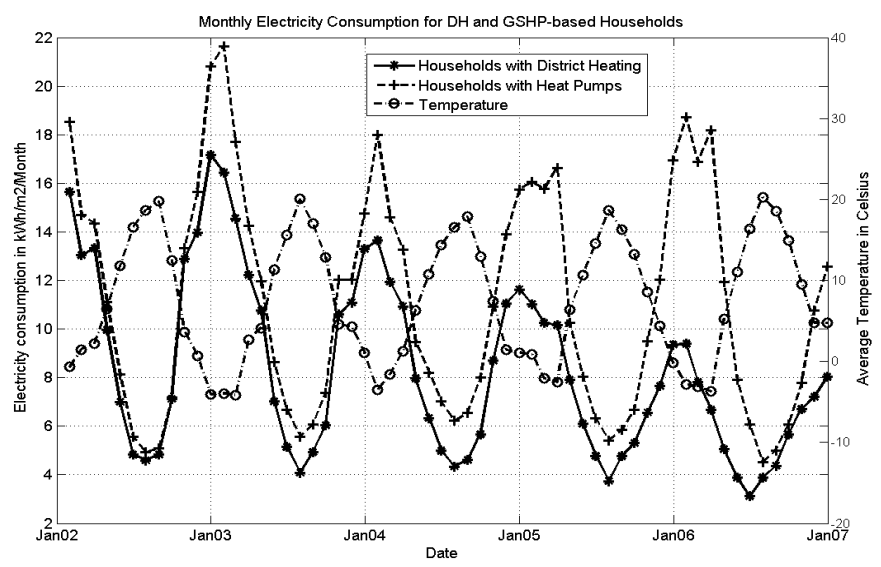

Fig. 6. Monthly electricity consumption for DH and GSHP-based households for the period 2002-2006.

By performing a monthly analysis and include average temperature data, greater understanding of the temperature impact on electricity use for GSHP-based households was obtained.

Electricity consumption between DH and GSHP-based households was very close during spring and autumn months, where nearly no heating or cooling is required; on the other seasons, especially during winter time, a great difference can be achieved.

The winter season of 2003 was in average the coldest of the 5 years analysed, the impact on GSHP-based households electricity use was accordingly; during that period of that year, the highest energy use was recorded. In contrast, the winter of 
2005 was the warmest, and therefore, the resulting energy use was the lowest.

An interesting phenomenon occurred during winter of 2006 where even when not the lowest temperatures were recorded, a very low average occurred from December of 2005 to February of 2006. This resulted in high electricity use from GSHP-based households over a longer period of time, so even if the spike was not as high as the one obtained in 2005, it ended in a higher overall electricity consumption for the whole season. On the other hand, the summer of 2006 was the warmest and therefore, electricity use was the lowest, helping balance the overall annual consumption.

What it is important to annotate from this is how even a slight change in the average temperature during cold months, can create a dramatic change in the energy use, especially with continuous days with below-zero temperatures, where GSHP reduce their operation efficiency.

\section{3) Hour of Day Use}

Annual and seasonal electricity consumption information is very important from the user point of view. It helps understand how the electricity bill will behave over the course of the year but it also could be used as a general system overview from the utility side. On the other hand, hour of the day use, is vital for maintaining supply-demand balance and to keep a balance grid.

In order to understand this hour-of-the-day behaviour for DH and GSHP-based households, the critical months of the year (January and February) were analysed and its hourly electricity usage was plotted to make a suitable comparison together with the hourly average temperature outside.

In year 2002, shown in Fig.7., the morning and evening consumption peaks can be easily noticed, as expected from typical household electricity-use behaviour; GSHP-based households, however, show a different consumption trend between the hours 00:00 and 03:00, matching the lowest temperatures of the day. Also during these three hours, the highest consumption difference between GSHP and DH-based households is obtained, reaching $20 \%$ more electricity consumption for GSHP users. The morning peak occurs at 7 am for both DH and GSHP users, and the difference in electricity use between them is $13 \%$. The afternoon curve slope is very similar between both users and it reaches a minimum-difference point at 17:00 when the difference reaches below 12\%; matching the cumulated lower GSHP-use during the warmest hours of the day. The evening peak is the highest of the day, and it occurs at 18:00 for GSHP users and 19:00 for DH users.

2003 had the coldest temperatures of the 5-year period. Its impact can be noticed on the high consumption peaks for GSHP users and a higher electricity-use difference between DH and GSHP users during the low-temperature first hours of the day. Also, GSHP users experienced a flatter and higher electricity use through the day, compared to 2002. The morning peak occurred at 07:00 for GSHP users and was the highest peak of the day, while it occurred at 08:00 for $\mathrm{DH}$ users and was the lowest of both daily peaks. The evening peak occurred at 19:00 for both users, during high-peak price time.

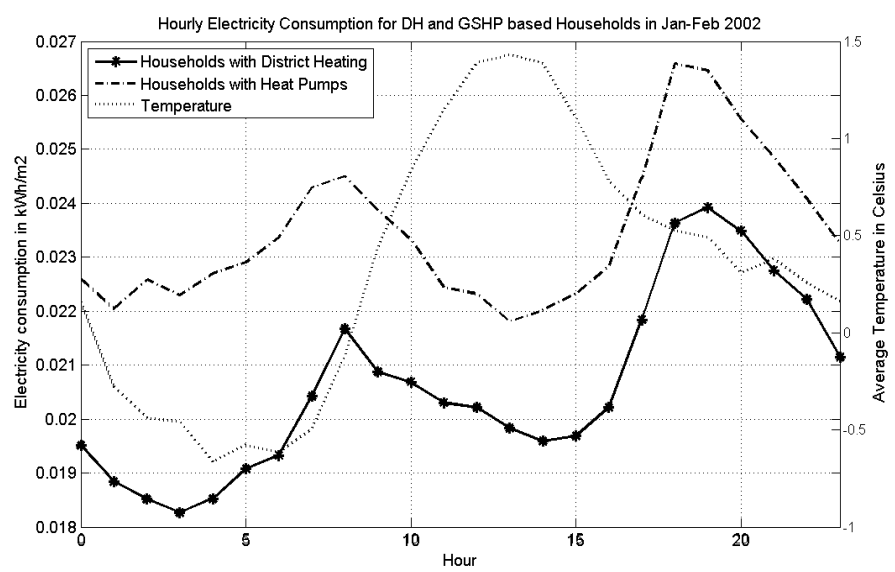

Fig. 7. Hourly Electricity consumption for DH and GSHP based households in the period January-February of 2002

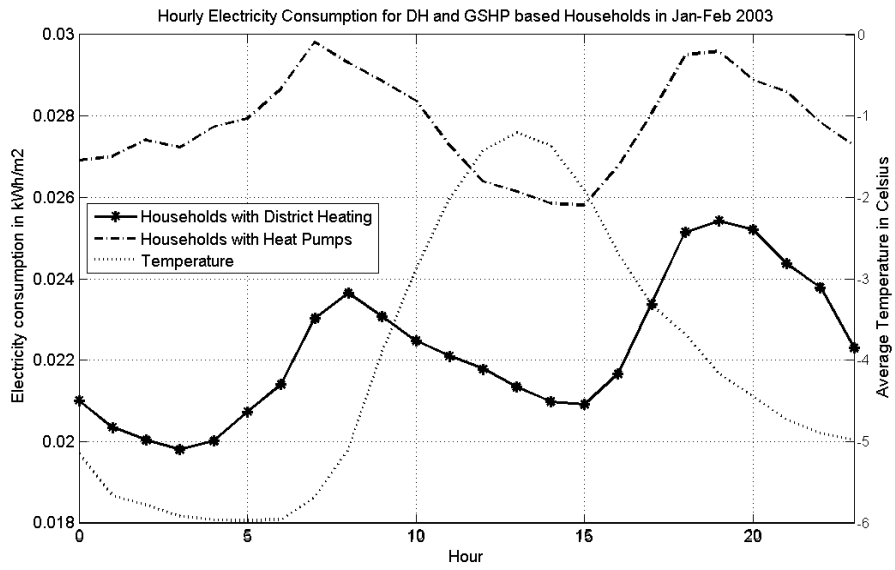

Fig. 8. Hourly Electricity consumption for DH and GSHP based households in the period January-February of 2003

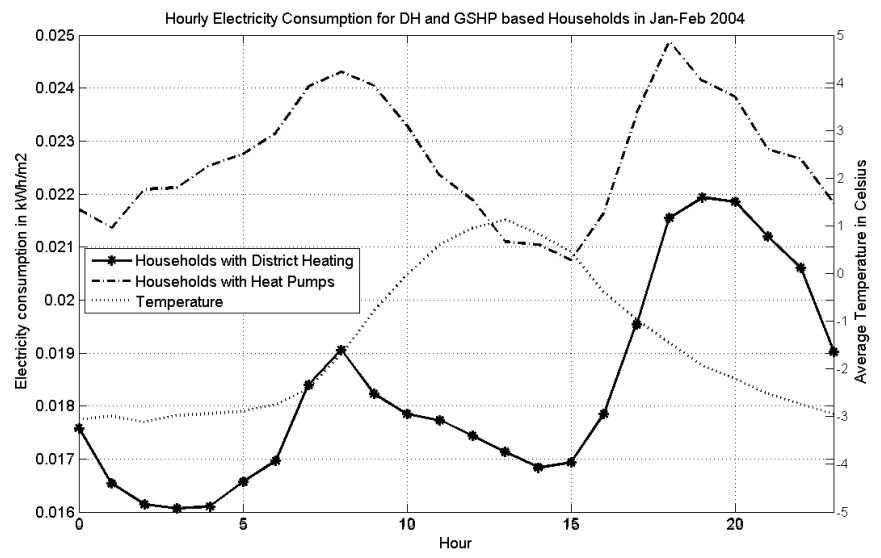

Fig. 9. Hourly Electricity consumption for DH and GSHP based households in the period January-February of 2004

The winter of 2004 was not as cold as the one in 2003, but it had a very cold February. This cold month impacted GSHP users' electricity consumption heavily. As a result, up to $40 \%$ electricity use difference was obtained between both users during the first 5 hours of the day. The morning peak occurred 
at 08:00 for both users, while the evening peak occurred at 19:00 for DH users and at 18:00 for GSHP users; this last one, however, had a very sharp consumption increase between 16:00 and 18:00 as shown in Fig. 9.

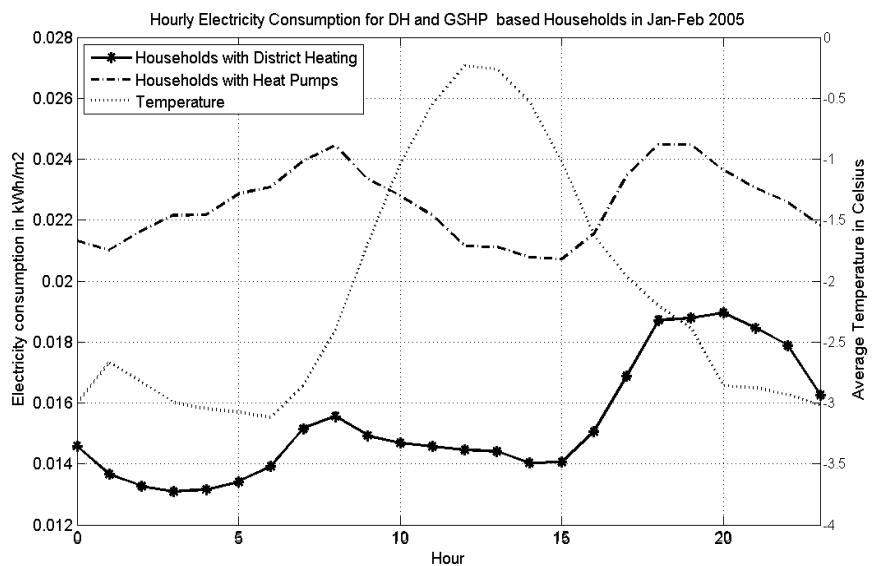

Fig. 10. Hourly Electricity consumption for DH and GSHP based households in the period January-February of 2005

The winter of 2005 experienced a very similar behaviour to the one obtained for the same period in 2004. An interesting effect occurred for the evening peak of DH users, since it shifted to 20:00 rather than 19:00 as obtained for previous years. The morning peak remained constant in time, occurring at 08:00 am for both users, followed by a period of lower electricity use, especially for GSHP, when outside temperatures reached warmer values. The evening peak for GSHP users occurred at 18:00, similar to previous years, however, not as sharp as the one obtained in 2004.

The winter of 2006 had the lowest average temperature during the whole season of the 5-year period analysed. Its impact on GSHP users was very severe, consuming twice as much electricity as users with DH-based systems. Average electricity use, however, was lower than the one obtained during the winter of 2003. The morning peak was very similar to the previous periods, for both users, occurring at $8 \mathrm{am}$, while a peak shifting occurred for the evening peak for DH users, having their highest electricity use at 20:00 compared to GSHP users, whose evening peak remained at 18:00.

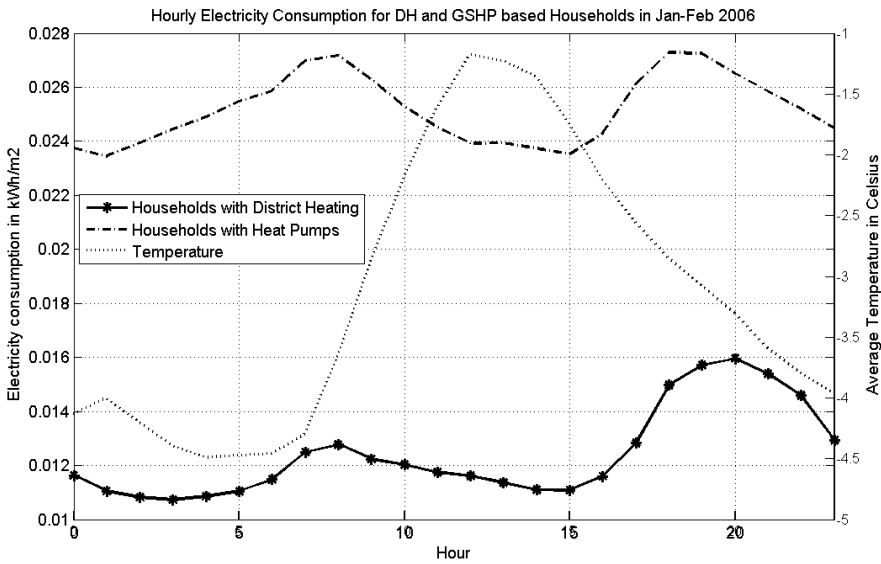

Fig. 11. Hourly Electricity consumption for DH and GSHP based households in the period January-February of 2006

\section{ACKNOWLEDGMENTS}

Thanks to Sollentuna Energi for providing the required customer's electricity use information and to all the users that participated in this project, for taking the time to respond to our questionnaires.

\section{CONCLUSIONS AND FUTURE WORK}

New installation of ground source heat pumps have maintained a constant increase over the past years, up to the point that Sweden has the highest amount of GSHPs installed in Europe. The main reason for this is the associated economic benefits. Several factors affect the electricity cost impact, but overall, there is a significant heating costs reduction opportunity, especially for households that previously had conventional electric water heaters, where savings per year of up to $58 \%$ were achieved.

GBHP therefore become a very cost-effective solution for one and two-dwelling households where access to DH is not possible. In multi-dwelling households, DSHP do not offer a similar significant economic benefit and in some cases can be more expensive in the long run so, DH systems are expected to maintain its predominant position for heating purposes in multi-dwelling houses.

Intensive use of GSHP has, however, several limitations; growing cost of the electricity in Sweden can increase the expected investment return time and become critical when tax exceptions for installing GSHP are not available anymore; another limitation is the high-peak price conditions during cold winters, the exact time when GSHP offer their lowest efficiency and are required the most.

On the bright side, intensive use of GSHP, also increases the opportunity for stimulating automatic demand-side management (ADSM) systems, where utilities can control the temperature settings of the GSHP, in order to provide a more stable demand-supply balance during peak-time conditions.

In order to make good use of ADSM systems, while maintaining users' temperature comfort, energy storage systems should be encouraged, as well as investments in thermal insulation, in order to increase ADSM systems effectiveness.

Consequently, it becomes absolutely necessary to make use of efficient dynamic pricing schemes that would encourage users make the best use of their GSHP without compromising the power system's demand balance, while maintaining a reasonable price for the end consumer.

To achieve this, development of simulation tools are necessary in order to provide a good decision support system for adopting the best available pricing schemes the new advanced metering systems are offering, combined with demand-response strategies such as heat storage during lowpeak times. 


\section{REFERENCES}

[1] Swedish Energy Agency, Energy in Sweden 2011, Eskilstuna, Sweden, 2011.

[2] F. Karlsson, M. Axell, and E. Technology, Heat Pump Systems in Sweden - Country Report for IEA HPP, pp. 1-29, 2003.

[3] Swedish Energy Agency, NUTEK's Heat Pump Competition, pp. 1-12, 1995.

[4] E. H. P. Association, M. Forsén, and T. Nowak, Outlook 2009: European Heat Pump Statistics, Brussels, Belgium, 2009.

[5] W. Goetzler, R. Zogg, H. Lisle, and J. Burgos, Ground-Source Heat Pumps: Overview of Market Status, Barriers to Adoption, and Options for Overcoming Barriers, 2009.

[6] Elektrizitäts-Gesellschaft Laufenburg AG, The Future Nordic Electricity Market: Power Flow Heading South - Prices North, EGL Research, 2006.

[7] NordREG, NordREG report on the price peaks in the Nordic wholesale market during winter 2009-2010, 2011.

[8] Statistiska Centralbyrån, Priser på elenergi och på överföring av el (nättariffer). http://www.scb.se/Pages/TableAndChart_85467.aspx. [Accessed: 22-Apr-2012].

[9] Swedish Energy Agency, Enkät- och fältundersökning av bergvärmepumpar, 2003.

[10] Bergvarmepumpar.n.nu, Bergvärmepumpar - besparing. [Online]. http://www.bergvarmepumpar.n.nu/bergvarmepumpar-besparing. [Accessed: 22-Apr-2012].

[11] J. Stromback, C. Dromacque, M. H. Yassin, G. Energy, and T. Tank, The potential of smart meter enabled programs to increase energy and systems efficiency: a mass pilot comparison Short name: Empower Demand, 2011.

[12] F. Wallin, C. Bartusch, E. Thorin, T. Bdckstrom, and E. Dahlquist, The use of automatic meter readings for a demand-based tariff, in Transmission and Distribution Conference and Exhibition: Asia and Pacific, 2005 IEEE/PES, 2005, pp. 1-6.

\section{BIOGRAPHIES}

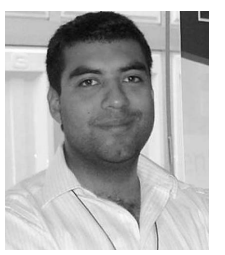

Javier Campillo is an Electronic Engineer (2003) and received his M. Sc. In Energy Engineering from Mälardalen University in Västerås, Sweden in 2007. He is currently a doctoral candidate at Mälardalen University working on developing mathematical models for forecasting electricity demand and simulating demand-response scenarios for Nordic countries.

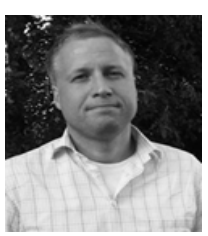

Fredrik Wallin received his Ph.D. degree in 2010 at Mälardalen University. He has been working for 10 years with energy information, metering systems and demandresponse issues. Other research interests are small-scale electricity production, renewable energy technologies and improved integration of energy consumers into the energy markets.

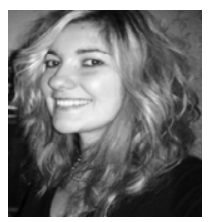

Iana Vassileva received her M. Sc. Degree in Environmental Science from Mälardalen University, Västerås, Sweden in 2007. She is now finishing her doctoral studies at Mälardalen University on energy consumption patterns and behaviour analysis and energy savings feedback improvement.

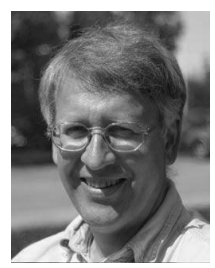

Erik Dahlquist received the Ph.D. degree in 1991. He is now a professor in Energy Technology at Mälardalen University. $\mathrm{He}$ has earlier worked at $\mathrm{ABB}$ as project manager and in different managing positions, in both research and business in the fields of process automation, power technology and energy systems. Dahlquist also is a member of the Royal Swedish Academy of Engineering, IVA. 